AUTORAS:

1. Bardin L (2004). Análise de conteúdo. Lisboa: Edições 70.

2. Batalha A (2004). Metodologia do ensino da dan Lisboa: Ediçōes.

3. Bautista R (Org.) (1997). Necessidades Educativas Especiais. Lisboa: Dinalivro.

4. Carmo H, Ferreira M (1998). Metodologia da investigação: guia para auto-aprendizagem. Lisboa: Universidade Aberta. 5. Correia L (2003). O sistema educativo Português as necessidades eductivas especins ou quendo e as no inclusão quer dizer exclusao. In: CORREIA L (Org.) Educação especial e inclusão - Quem disser que uma sobrevive sem a outra não está no seu perfeito juízo. Porto: Porto Editora.

6. Ferraz CRA, Araújo MV e Carreiro LRR (2010). Inclusão de crianças com síndrome de down e paralisia cerebral no ensino fundamental I: comparação do relato de mães e professores. Rev Bras Educ Esp 16(3): 397-414. 7. Franco G (2000). Psicologia no Esporte e na Atividade Física. São Paulo: Editora Manole.

8. Gehres A (2009). Inclusive Dance Education: an experience with Trissomy 21. In: DaCi Conference 2009. Proceedings of cultures flex: unearthing expressions of the dancing child. Kingston-Jamaica, 29-35.

9. Gough M (1993). In touch with dance. Lancaster: Whitethorn Books.

10. Jezine E, Júnior RPA (2011). Desafios da inclusão en Portugal: a importância das atividades de tempo livre na promoção das aprendizagens. Rev Lusóf Educ 19: 37-66. 11. Lessard-Hébert M, Goyette G, Boutin G (2005). In-

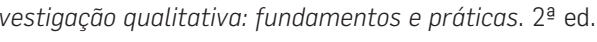
Lisboa: Piaget.

12. Luiz FMR, Nascimento LC (2012). Inclusão escolar de crianças com síndrome de down: experiências contadas pelas famílis Rev Bras Educ Esp 18(1): 127-140.

M.

(1999). Ensino de dança hoje: textos e contextos. São Paulo: Cortez.

14. Nielsen B (1999). Necessidades educativas especiais na sala de eula: um guia para professores. Porto: Porto Editora.

15. Oliveira-Menegatto LM, Martini FO, Lip LK (2010). Inclusão de alunos com síndrome de down: discurso dos professores. Fractal: Rev Psicol 22(1): 155-168. 16. Organização Mundial de Saúde. (2012). Relató io Paulo: SEDPCD.

17. Palha M (2005). Sindroma de down: leitura e escrita. Um guia para pais, educadores e professores. Porto: Porto Editora. educação inclusiva. In: Rodrigues D. ed. Educação inclu
Monique Marques Longo $^{1}$

Isis Gabrielli Gomes Xavier co para a Educação Física e Desporto Escolar. Portugal.

\section{A formação de professores de educação física escolar infantil no Brasil}

Universidade do Estado do Rio Janeiro, Rio de Janeiro, Brasil siva. estamos a fazer progressos? Lisboa: FMH Edições. 20. Rodriguéz J (1996). Jugando y aprendiendo juntos: un modelo de intervención didáctico para favorecer el desarrollo de los niños y niñas con síndrome de Down. Málaga: Ediciones Aljibe.

1. Roldão MC (2003). Diferenciação curricular revisiada: conceito, discurso e praxis Porto: Porto Editora. 22. Sampedro M, Blasco G, Hernández A (1993). A criança com síndrome de down. In: Bautista R. ed. Necessidades Educativas Especiais. Lisboa: Dinalivro. 23. Sassaki R (2006). Inclusão/ construindo uma sociedade para todos. Rio de Janeiro: WVA.

24. Serre J (1982). Les etudes et la recherche en danse à l'Université de Paris-Sorbonne. La Recherche en Danse 1: 5-20.

25. Smith-Autard $J(1990)$. The art of dance in education. Londres: A \& C Black.

26. Sousa A (2003). Educação pela arte e artes na educação: drama e dança. Vol. 2. Lisboa: Instituto Piaget. 27. Sousa J (2006). Desporto escolar: um instrumento estratégico para o desenvolvimento de Portugal. Disponível em www.congressododesporto.gov.pt.

28. Trivinos ANS (1995). Introdução à pesquisa em ciências sociais. 4ae ed. São Paulo: Atlas.

29. Unesco (2005). Orientações para a inclusão: garantindo o acesso à educação para todos. Paris: UNESCO.

30. Unesco (1994). Necessidades educativas especiais: declaração de Salamanca/ enquadramento da ç̧ão. Paris: UNESCO. https://doi.org/10.5628/rpcd.17.03.63

PALAVRAS CHAVE:

Formação docente.

Educação física escolar infantil.

Politicas educacionais brasileiras.

SUBMISSAO: 07 de Março de 2017

ACEITAÇÃO: 10 de Setembro de 2017

\section{RESUMO}

A promulgação da Lei de Diretrizes e Bases da Educação 9394/96, que rege o atual sistema brasileiro de educação impõe, de forma inédita no país, a obrigatoriedade da educação física como componente curricular escolar e a Educação Infantil como primeira etapa da Educação Básica. A formação docente torna-se objeto de discussão quando, até dezembro de 2015, nenhuma diretriz determinava a obrigatoriedade do profissional da educação para lecionar neste seguimento. Este artigo apresenta uma pesquisa de natureza qualitativa em cinco cursos de Pedagogia e Educação Física em uma universidade brasileira visando compreender como graduandos estão sendo formados para lecionar neste seguimento. Os procedimentos metodológicos residiram na análise documental dos currículos e ementas destes cursos e aplicação de entrevistas semi-estruturadas com licenciados, categorizadas segundo a análise de conteúdo proposta por Bardin ${ }^{(3)}$. Wajskop ${ }^{(21,22)}$, Ayoub (2), Strazzacaapaa ${ }^{\left({ }^{16)}\right)}$, Bento ${ }^{(4)}$, Tardif ${ }^{(18)}$, e Nóvoa ${ }^{(12)}$ nos aportaram teoricamente. Como resultados observamos a falta de disciplinas de Educação Física nos currículos de pedagogia, o despreparo e insegurança dos graduandos de pedagogia para dar aulas de Educação Física e as possíveis consequências causadas às crianças sob a regência de aulas não lecionadas por profissionais formados em cursos superiores de Educação Física cuja prática é ainda visível no cotidiano das escolas brasileiras.

Correspondência: Monique Marques Longo, Rua São Francisco Xavier, 524, 90 andar, IEFD - UERJ Maracanã, Rio de Janeiro, RJ, Brasil Cep: 20550-900. (moniquem!@globo.com) 
The training of physical education

\section{teachers in Brazil}

\section{ABSTRACT}

The promulgation of the Law on the Guidelines and Bases of Education 9394/96, which governs the current Brazilian system of education, imposes, in an unprecedented way in the country, the obligation of Physical Education as a school curricular component and the Child Education as the first stage of basic education. Teacher training becomes the subject of discussion when, by December 2015, no guideline determined the obligation of the education professional to teach in this follow-up. This article presents a qualitative research in five courses of Pedagogy and Physical Education in a Brazilian university aiming to understand how graduates are being trained to teach in this follow up. The methodological procedures resided in the documental analysis of the curriculum of these courses and the application of semi-structured interviews with graduates, categorized according to the content analysis proposed by Bardin ${ }^{(3)}$. Wajskop ${ }^{(21,22)}$, Ayoub ${ }^{(2)}$, Strazzacaapaa ${ }^{(16)}$, Bento ${ }^{(4)}$, Tardif ${ }^{(18)}$, and Nóvoa ${ }^{(12)}$ contributed theoretically. As a result, we observed the lack of Physical Education subjects in pedagogy curriculum, the lack of preparation of undergraduates for teaching Physical Education, and the possible consequences for children under the tuition not taught by Physical Education graduates, still visible in the daily life of Brazilian schools.

\section{KEY WORDS}

Teacher training. Child school physical education.

Brazilian educational politics.

\section{INTRODUÇÃo}

No Brasil, desde 1996, o Sistema Nacional de Educação é regido pela Lei de Diretrizes e Bases da Educação Nacional (LDBEN) número 9394/96 (7), cujo fim reside em garantir os princípios inerentes à Constituição Brasileira de 1988. A LDBEN/96 caracteriza-se por ser a terceira lei promulgada no país visando estabelecer princípios, deveres e direitos básicos aos diversos estabelecimentos brasileiros de ensino. Caracterizada pela inédita garantia da gestão democrática e autônoma das diversas unidades escolares, a LDBEN/96 representou um grande avanço em relação às diretrizes impostas pela primeira LDBEN de 1961 , e a segunda implementada em 1971. Dentre as peculiaridades da Lei, ressalta-se a obrigatoriedade da formação dos professores em Instituições de Ensino Superior (IES) para todos os seguimentos da Educação Básica, exceto para a Educação Infantil, onde amplia a possibilidade de formação docente aos Cursos Normais de Ensino Médio.

A LDBEN/96 ${ }^{(7)}$ constitui-se de 92 artigos, sendo o $26^{\circ}$ direcionado à obrigatoriedade inédita da disciplina de educação física como componente curricular das escolas. Determina-se que "a Educação Física deve ser integrada à proposta pedagógica da escola, como componente curricular da Educação Básica, ajustando-se às faixas etárias e às condições da população escolar" (LDBEN/96 ${ }^{(7)}, 26^{\circ}$ artigo). Para isto, em 1997 são apresentados, pelo Ministério de Educação, Parâmetros Curriculares Nacionais ${ }^{(5)}$ (PCN's) específicos aos professores de cada disciplina do Ensino Fundamental.

No que concerne às etapas da Educação Básica oferecida e garantida pelo Estado Brasileiro, a LDBEN/96 (7), em seu artigo 29, prorroga pela primeira vez a Educação Infantil como primeira etapa da Educação Básica, retirando creches e pré-escolas da tutela da Secretaria de Assistência Social. A lei passa a impor aos municípios o oferecimento de creches aos bebês e pré-escolas às crianças brasileiras até seis anos.

É fato o avanço promovido pela lei, mas impõe-se um desafio aos professores de construírem propostas pedagógicas e metodológicas que atrelem a abordagem do movimento humano às especificidades da criança de zero a seis anos. A obrigatoriedade da Educação Física nos currículos escolares representa uma crescente conscientização da importância, ratifica Burguer e Krug ${ }^{(8)}$, atribuída à criança e à Educação Infantil, pois não se concebe mais esta como apenas uma boa política assistencial, mas sim com estabelecimentos específicos com orientações e práticas pedagógicas apropriadas", algo que se torna relevante num cenário de desvalorização da prática e da sua profissionalização.

No sentido de regular saberes curriculares da Educação Infantil, o Ministério de Educação e Cultura (MEC) publicou o Referencial Curricular Nacional da Educação Infantil (6) (RCNEI). Neste são expostos objetivos a serem alcançados e conteúdos abordados pelos professores na Educação Infantil. 
Especificamente aos conteúdos referentes à Educação Física, observamos no terceiro volume do RCNEI (6), a proposta da abordagem do movimento como conteúdo a ser trabalhado junto às artes visuais, linguagem oral, escrita, a natureza, sociedade. 0 conceito e/ ou disciplina "Educação Física" não é exposto, e nem diretrizes são apresentadas pelo MEC em relação à área especificamente. 0 não direcionamento do documento nos faz considerar a não especificidade da formação docente a esse seguimento, abrindo espaço para que professores generalistas ministrem esses conteúdos, sem a exigência do profissional de Educação Física na escola.

Dentre os muitos questionamentos que atravessam, portanto, a prática da cultura corporal do movimento em creches e pré-escolas, encontra-se o locus da formação docente,

Tardif ${ }^{(18)}$, nesse sentido, se dedica a pensar a formação docente e, sobretudo, a relação dos professores com os saberes necessários à sua atuação profissional. Para o autor, estes são alcançados por meio de diversas fontes, das quais a formação inicial recebida nos Cursos de Graduação é parte essencial, já que se constitui espaço específico de organização curricular. Porém, segundo Tardif ${ }^{(18)}$, não é locus exclusivo da formação docente. 0 formar-se docente pressupõe compreender a constante complexidade de elementos que constituem os saberes docentes. Defini-los implica ratificar que suas fontes se circunscrevem não apenas aos conhecimentos disciplinares - negociados nos cursos superiores - mas também aos saberes negociados pelas ciências da educação, na relação entre pares e habilidades desenvolvidas durante nossa prática cotidiana docente.

Nóvoa ${ }^{(12)}$ complementa a discussão ressaltando que a escola se constitui como territorialidade espacial e cultural onde se concretiza relações múltiplas entre os diversos atores educativos. Sua compreensão, portanto, exige a mobilização de dimensões pessoais, simbólicas e políticas dos atores ali envolvidos, não reduzindo o pensamento e a ação educativa à perspectiva técnica e ou gestacional. Tais reflexões devem, portanto, balizar a formação daquele que se inserirá nas escolas.

Podemos pensar que a prática pedagógica é desafiada de forma cotidiana por tensões e negociações, fazendo do ato de ensinar um constante exercício de transformação de sua própria identidade, o que implica capacidades de análises, reflexão e desconstrução constantes - algo que deve ser fomentado também no decorrer dos Cursos de Graduação. Se uma pessoa ensina por trinta anos, ressalta Tardif (18) "ela não faz simplesmente alguma coisa, ela faz também alguma coisa de si mesma: sua identidade carrega as marcas da sua própria atividade" (p. 53)

Bento ${ }^{(4)}$, no que concerne à prática específica do docente de Educação Física, postula que suas formações se presentificam como espaços de estruturação das unidades pedagógicas e organizativas básicas, sendo essencial ao processo de ensino, que, por sua vez, se concretiza na prática cotidiana da escola. No entanto, o que observamos na atualidade é que mudanças na estruturação socioeconômica da população, nas formações familiares, de educação ética das crianças, provocam modificações, também, na estruturação das au- las de Educação Física e objetivos a serem alcançados. Consequentemente, evidenciamos hoje a urgência de se estabelecer a legitimação de uma formação docente de qualidade em Cursos de Ensino Superior, estruturados para pensar e repensar a escola com suas especificidades temporais e culturais

Até dezembro de 2015 , quando se sancionou o projeto de lei $3002 / 2014{ }^{(13)}$, nada era exposto na legislação vigente sobre a formação do profissional que lecionaria a disciplina obrigatória de Educação Física às crianças de até seis anos. Tal vácuo permite que pedagogos, egressos dos Cursos Normais ou professores regentes das turmas de maternal e pré-escolares propusessem aos alunos aulas de psicomotricidade e/ ou afins.

0 projeto de lei $n^{\circ} 3002 / 2014{ }^{(13)}$, de autoria do deputado Leonardo Tutuca, passou a determinar a presença de profissionais licenciados em Cursos Superiores durante as aulas de educação física na Educação Infantil. Alega-se, no projeto de lei, que a criança até os seis anos tem uma formação neuromotora incompleta, podendo, o estímulo incoerente ao seu nível de desenvolvimento, ser prejudicial a sua maturação. Segundo o projeto de lei, a consecução de tal aprendizagem somente pode ser garantida quando proposta por um profissional formados em nível superior. Como o projeto de lei será ainda sancionado, a regulação nas escolas ainda não acontece, fato que corrobora a perpetuação da prática das aulas de Educação Física operacionalizadas pelos regentes professores de sala-de-aula.

Alguns estudos (e.g., Negrine ${ }^{(11)}$, Ayoub ${ }^{(2)}$, Burger e Krug ${ }^{(8)}$ ) ratificam tal prática. As aulas de Educação Física no cotidiano das instituições de Educação Infantil apresentam, salienta Ayoub (2, p.53), uma "organização afinada com os princípios de uma pedagogia (..) qual compete a professora generalista o desenvolvimento das diversas atividades curriculares". A Educação Física, ou mesmo as aulas intituladas psicomotricidade, eram e ainda são, segundo a autora, mote de discussão tanto sobre a formação do profissional responsável, quanto da organização do tempo escolar e sua disciplinarização. Negrine ${ }^{(11)}$, de forma semelhante, acusa uma falta de argumentos consistentes que ratifiquem a ainda evidente unidocência na Educação Infantil e, às vezes, dos primeiros seguimentos do ensino fundamental nas escolas brasileiras.

Ante tais reflexões preliminares, mostrou-se relevante compreender como pedagogos e profissionais de educação física estão sendo formados para ministrarem aulas de Educação Física nas instituições de Ensino Infantil. Nesse sentido, o artigo aqui apresentado expõe dados de uma pesquisa empírica focada em analisar a atual formação de pedagogos e professores de Educação Física escolar infantil. Para tal, apresentaremos as possíveis vacuidades da formação de pedagogos para lecionarem tais aulas em creches e pré-escolas e problematizamos, ainda e por fim, os possíveis prejuízos ao desenvolvimento motor, e sobretudo, integral de bebês e criança, decorrente de aulas não ministradas por profissionais de educação física devidamente formados em IES. 


\section{MATERIAL E MÉTODO}

Epistemologicamente, a pesquisa aqui apresentada utiliza-se dos liames dos estudos qualitativos, subentendendo a construção dos dados como decorrentes da consideração e exposição descritiva da relação complexa existente entre sujeito (pesquisador) e objeto (a ser pesquisado). Utilizamos como procedimentos metodológicos, a análise de conteúdo documental baseados nas referências de Antunes ${ }^{(1)}$ e a prática de entrevistas semiestruturadas analisadas segundo o método de análise de conteúdo proposto por Laurence Bardin ${ }^{(3)}$

No que concerne à análise das entrevistas, cabe lembrar que os estudos de natureza qualitativa - como é o caso da aqui exposta realizada com 13 graduandos de Pedagogia devem ser analisados, afirmam Silva e Fossa (14), "de forma diferente dos dados provenientes de estudos de abordagem quantitativa, que se valem de softwares estatísticos, testes de hipóteses, estatística descritiva e multivariada". Tal técnica ainda pode ser compreendida como meio de analisar o que foi dito nas entrevistas ou observado pelo pesquisado, de forma a classificá-los em temas ou categorias que, segundo ainda Silva e Fossa, "auxiliam na compreensão do que está por trás dos discursos".

O local de inserção da pesquisa residiu na Faculdade de Educação de uma Universidade pública localizada na cidade do Rio de Janeiro, Brasil. Nesta, os currículos de pedagogia e educação física foram analisados visando apreender as disciplinas e ementas que se direcionassem à educação infantil, às crianças de zero à seis anos ou, especificamente, à formação do profissional para lecionar aulas de Educação Física em creches e pré-escolas Num segundo momento, treze graduandos matriculados nos cursos de Pedagogia desta mesma instituição foram entrevistados, visando compreender suas impressões e inquietações acerca da abordagem de atividades psicomotoras e/ou da prática de ministrar aulas de Educação Física ao primeiro seguimento da Educação Básica.

As categorias de análise foram organizadas especificamente em cada quadro de perguntas feitas durante as entrevistas. Por exemplo, na pergunta 4, analisada no quadro 4 no texto, tínhamos como objetivo compreender qual era a importância dada pelos futuros pedagogos à prática da Educação Física nas aulas de Ensino Infantil. As categorias inferidas foram: (a) contribui para o desenvolvimento global, (2) brincadeira, (3) coordenação motora (4) não se limita ao conteúdo, (5) hábitos saudáveis, (6) esporte, (7) descarregar energia, (8) mais focadas. A partir delas as respostas apresentadas pelos graduandos foram agrupadas para análise, assim como aporta metodologicamente Bardin ${ }^{(3)}$.

Os seguintes fluxogramas foram obtidos através do site da instituição no período de $01 \mathrm{a}$ 10 de Outubro de 2015: (a) Licenciatura em Educação Física, versão 9; (b) Licenciatura em Pedagogia da Faculdade de Formação de Professores versão 4, (c) Licenciatura plena em Pedagogia da Faculdade de Educação da Baixada Fluminense, versão 3; (d) Licenciatura plena em Pedagogia da Faculdade de Educação, versão 2, (e) Licenciatura plena em Pedagogia da Faculdade de Educação, modalidade à distância, versão 2.
No que concerne ao aporte teórico, principalmente Silveira ${ }^{(15)}$, Scrazzcappa ${ }^{(16)}$, Ayoub (2), Wajiskop ${ }^{(21,22)}$ e Tisi ${ }^{(18)}$ serviram de referência às discussões aqui apresentadas. Todos os autores trouxeram informações relevantes à interpretação dos dados da pesquisa, como ao fornecer novas reflexões à temática discutida.

\section{RESULTADOS}

10 MOMENTO DA PESQUISA: ANÁLISE CURRICULAR

Visando compreender a formação de professores nos cursos de Pedagogia e de Educação Física analisamos os fluxogramas de cinco cursos de licenciatura em Educação Física e Pedagogia da Faculdade de Educação de uma Universidade localizada na cidade do Rio de Janeiro/ Brasil. No fluxograma de licenciatura em Educação Física foram encontradas cinco disciplinas que estão direcionadas diretamente à Educação Infantil: Desenvolvimento Motor Aplicado à Educação Física; Aprendizagem Motora Aplicada à Educação Física I; Aprendizagem Motora Aplicada à Educação Física II; Recreação na Educação Física e Educação Física Escolar Infantil.

Analisando as ementas das disciplinas, inferimos que possivelmente elas trazem um embasamento teórico consistente em relação ao desenvolvimento motor, cognitivo, afetivo e sociocultural que são fundamentais para estruturar atividades que desenvolvam as capacidades postuladas pelo RCNEI. As três primeiras disciplinas encontradas no fluxograma de educação física se direcionam a fundamentar os futuros professores a discutirem tanto aspectos inerentes ao desenvolvimento motor, suas especificidades biomecânicas, fisiológicas e anatômicas, como os aspectos afetivos, cognitivos e sociais que influem na sua equilibrada aquisição. As disciplinas de Recreação e, especificamente, de Educação Física Escolar Infantil, potencialmente fundamentam os alunos a refletirem sobre a multiplicidade de discursos construídos historicamente sobre a infância e estratégias para mediarem a aprendizagem destas com elementos da cultura corporal do movimento. Tais conteúdos mostram-se imprescindíveis àqueles que lecionarão no primeiro seguimento da Educação Básica.

No currículo dos cursos de Pedagogia desta Universidade encontramos uma única disciplina que supostamente abordaria reflexões sobre a Educação Física Escolar Infantil. Esta se intitula Educação, Artes e Ludicidade e em sua ementa há um tópico que se referente à importância do jogo e da brincadeira no processo de conhecimento, expressividade e socialização da criança.

No fluxograma de Pedagogia da Faculdade de Educação da Baixada Fluminense foi encontrada uma outra disciplina próxima à Educação Física Escolar Infantil. Ela está intitulada como Arte, Movimento e Ludicidade. Na ementa dessa disciplina consta a abordagem dos jogos e brincadeira populares, jogos e esportes na escola, danças e atividades rítmicas. Apesar de mais abrangente que a anterior, tal disciplina não abarca aspectos fisiológicos, anatofisiológicos, neuromotores e/ ou biomecânicos inerentes à aprendizagem do movimento humano. 
No curso de Pedagogia da Faculdade de Educação I, uma disciplina intitulada $O$ lúdico e a Educação Infantil apresenta na sua ementa o brincar como expressão da criança, a dimensão cultural do brincar, e o brincar na educação infantil.

No curso da Faculdade de Educação, modalidade à distância, evidenciamos uma disciplina intitulada Corpo e Movimento na Educação. A sua ementa apresenta como um dos objetivos compreender a importância do jogo e do brinquedo na construção do conhecimento. De todas as disciplinas observadas nos cursos de Pedagogia, essa é a que mais se aproxima da realidade da Educação Física, com um repertório mais amplo sobre a criança. No entanto, estão claros os limites de formação que uma única disciplina curricular possa fornecer frente a exigência de uma formação consistente a um profissional responsável por educar a criança motora e integralmente. Nos aprofundaremos na discussão no tópico da discussão final.

$2^{\circ}$ MOMENTO DA PESQUISA: ENTREVISTAS

Relembramos que o objetivo dessa análise curricular residiu em compreender como pedagogos, mas também professores de Educação Física, estão sendo formados no que consiste a operacionalizar as propostas dos RCNEI ao seguimento da Educação Infantil. A realidade que encontramos nas escolas é de que, devido à não obrigatoriedade de profissionais formados em licenciatura em Educação Física para ministrar tais aulas, até a aprovação do projeto de lei no. $3002 / 2014^{(13)}$, pedagogos e normalistas se esforçam para dar conta das propostas da Educação Física apregoada pelo RCNEI ${ }^{(6)}$, enquanto donos de creches e préescolas não recorrem aos profissionais formados na área. Por isso, também cabe escutar como os próprios futuros pedagogos se sentem ante tal função.

Treze graduandos matriculados nos últimos períodos dos seus cursos de pedagogia foram entrevistados. As inferências foram construídas com base no método de análise de conteúdo proposto por Laurence Bardin ${ }^{(3)}$. Apresentaremos as categorias construídas a posteriori com base nas respostas apresentadas em tabelas, as quais serão analisadas previamente a sua apresentação.

A média de idade das entrevistadas é de 22 anos. Elas, todas mulheres e escolhidas aleatoriamente, estavam no 6o período da graduação e nenhuma possuía uma graduação anterior.

0 quadro 1 refere-se à experiência em estágios supervisionados. Setenta e seis por cento já tinham realizado estágio na Educação Infantil, o que nos faz inferir certa experiência na prática cotidiana deste seguimento. Este fato corrobora a importância e validade das respostas ulteriormente aqui apresentadas acerca das suas dificuldades cotidianas profissionais. Estágios em outros espaços de educação não formal também foram citados demonstrando a abrangência das possibilidades profissionais da área.

\begin{tabular}{llcc}
\hline RESPOSTA & QUAL? & QUANTIDADE & PORCENTAGEM \\
\hline \multirow{3}{*}{\begin{tabular}{llcl} 
Sim 13 \\
\multirow{2}{*}{ Não 0}
\end{tabular}} & Biblioteca /Parque Estadual & 1 & $7.69 \%$ \\
\cline { 2 - 4 } & Educação Infantil & 10 & $76.92 \%$ \\
\cline { 2 - 4 } & Ensino Fundamental & 2 & $23.07 \%$ \\
\cline { 2 - 4 } & Ensino Médio & 5 & $15.38 \%$ \\
\cline { 2 - 4 } & Movimentos Sociais e Instituição & 1 & $38.46 \%$ \\
\cline { 2 - 4 } & Pedagogia Empresarial & $1.69 \%$ \\
\hline
\end{tabular}

O segundo quadro constitui-se da resposta à pergunta: "Na sua grade curricular existe alguma disciplina específica de Educação Física na Educação Infantil?". Os resultados retrataram a escassez de disciplinas nos currículos de Pedagogia. Apenas $7 \%$ respondeu que existe uma disciplina, eletiva, na grade. Tal fato infere que muitos pedagogos se formam sem realizar nenhuma disciplina especifica que aborde temas direcionados à educação física. 0s 76.9\% que alegaram não existir nenhuma informação sobre atividades psicomotoras ou corporais durante o seu curso ressaltaram a dicotomia entre sua formação e exigências práticas surgidas durante seus estágios.

QUADRO 2. Disciplinas específicas de Educação Física na Educação Infantil na grade de Pedagogia

\begin{tabular}{llccc}
\hline RESPOSTA & INFERÊNCIAS/CATEGORIAS & INDIVÍDUOS & QUANTIDADE & PORCENTAGEM \\
\hline \multirow{3}{*}{ Não(12) } & Disciplina eletiva & $\mathrm{A} 5$ & 1 & $7.69 \%$ \\
\cline { 2 - 5 } & Nunca ouviu sobre o tema & $\mathrm{A} 11$ & 1 & $7.69 \%$ \\
\cline { 2 - 5 } & Não Justificaram & $\mathrm{A} 1, \mathrm{~A} 2, \mathrm{~A} 3, \mathrm{~A} 4, \mathrm{~A} 6, \mathrm{~A} 8$, & 10 & $76.92 \%$ \\
\hline \multirow{2}{*}{$\mathrm{Aim}(1)$} & Disciplina eletiva & $\mathrm{A} 7 \mathrm{~A}$, A & 1 & $7.69 \%$ \\
\hline
\end{tabular}

0 terceiro quadro demonstra a insegurança dos futuros pedagogos ministrarem aulas de Educação Física para a Educação Infantil - somente uma aluna respondeu que se sentiria segura, porém pesquisaria mais sobre 0 assunto. As inferências nos fazem questionar se uma pesquisa autodidata promoveria a compreensão plena sobre quais são os objetivos da Educação Física, metodologias adotadas, e as especificidades da abordagem da cultura corporal do movimento a crianças nessa faixa etária. Essa mesma graduanda se contradiz, posteriormente, pois em sua justificativa defende que cada profissional deveria atuar na sua área específica. Das 13 alunas entrevistadas, 12 responderam que não se sentiriam seguras. Em suas respostas, alegavam a falta de informação sobre os aspectos inerentes à área, bem como a importância de se manter a especificidade dos profissionais em ques- 
tão. Uma aluna ainda ressaltou o fato de haver risco para as crianças caso a prática de aulas fosse realizada por profissionais não formados na área.

QUADRO 3. Insegurança para ministrarem aulas de Educação Física para a Educação Infantil.

\begin{tabular}{|c|c|c|c|c|}
\hline RESPOSTA & INFERÊNCIAS/CATEGORIAS & INDIVÍDUOS & QUANTIDADE & PORCENTAGEM \\
\hline \multirow{2}{*}{$\operatorname{Sim}(1)$} & Pesquisaria sobre 0 assunto & A9 & 1 & $7.69 \%$ \\
\hline & Cada profissional na sua área & A9 & 1 & $7.69 \%$ \\
\hline \multirow{5}{*}{ Não (12) } & $\begin{array}{l}\text { Nenhuma disciplina ligada ao tema/ } \\
\text { Sem formação especifica }\end{array}$ & $\mathrm{A} 6, \mathrm{~A} 7, \mathrm{~A} 10, \mathrm{~A} 12$ & 4 & $30.76 \%$ \\
\hline & Pouco conhecimento & A5, All & 2 & $15.38 \%$ \\
\hline & Insegurança & A6, All & 2 & $15.38 \%$ \\
\hline & Risco para as crianças & A7 & 1 & $7.69 \%$ \\
\hline & $\begin{array}{l}\text { Não deve se restringir aos professores } \\
\text { de educacaão física }\end{array}$ & A8 & 1 & $7.69 \%$ \\
\hline
\end{tabular}

Quanto à importância da educação física (QUADRO 4) a resposta foi unânime e 46\% justificou sua importância para o desenvolvimento global. Go Tani ${ }^{(17)}$ deixa claro que a Educação Física, independente da área de atuação, trabalha com o movimento, e é inegável a sua contribuição ao desenvolvimento global do ser humano, desde que seja abordado de forma adequada. 0 fato é compreendido pelas alunas, que ainda ressaltaram o desenvolvimento da coordenação motora, a promoção de hábitos de vida saudáveis e a exploração do seu corpo. Quatorze por cento fundamentou sua importância ressaltando o papel que profissional de Educação Física tem em ajudar a criança a estruturar o campo da brincadeira, objetivo apresentado pelo RCNEI ${ }^{\left({ }^{6}\right)}$. A brincadeira é uma das formas de linguagem infantil que se instaura no plano da imaginação indicando o grau de domínio da linguagem simbólica por parte daquele que brinca. Relembramos que, segundo o RCNEI (6, p. 27) "toda brincadeira é uma imitação da realidade ressignificada, no plano das emoções e ideias"; prática, portanto, necessária à apreensão do mundo pela criança.

Sete por cento ressaltou a importância da Educação Física recorrendo à ideia de mecanismo de lazer, tempo/ espaço para "descarregar energias". Outros 7\% ressaltou sua importância como espaço alternativo à aprendizagem teórica/ cognitiva, respostas que corroboram a recorrência do ideário cartesiano que atravessa atores e projetos políticos ainda hoje nas escolas.

\begin{tabular}{|c|c|c|c|c|}
\hline RESPOSTAS & INFERÊNCIAS/CATEGORIAS & INDIVÍDUOS & QUANTIDADE & PORCENTAGEM \\
\hline \multirow{9}{*}{$\begin{array}{l}\text { Sim (13) } \\
\text { Não (0) }\end{array}$} & Atividade direcionada & Al & 1 & $7.69 \%$ \\
\hline & Contribui para o desenvolvimento global & $\begin{array}{c}\mathrm{A} 2, \mathrm{~A} 4, \mathrm{~A} 8, \mathrm{~A} 9 \\
\mathrm{~A} 10, \mathrm{~A} 12\end{array}$ & 6 & $46.15 \%$ \\
\hline & Brincadeira & A2 & 1 & $7.69 \%$ \\
\hline & Coordenação motora & $A 3, A 5, A 7$ & 3 & $23.07 \%$ \\
\hline & Não se restringi ao aprendizado do conteúdo & A4 & 1 & $7.69 \%$ \\
\hline & Hábitos saudáveis & A11, A13 & 3 & $23.07 \%$ \\
\hline & Esporte & A10 & 1 & $7.69 \%$ \\
\hline & Descarregar energia & A6 & 1 & $7.69 \%$ \\
\hline & Mais focadas & A6 & 1 & $7.69 \%$ \\
\hline
\end{tabular}

As respostas do quadro 5 baseiam-se nas impressões discentes sobre a relação desenvolvimento motor e cognição. Todas as alunas afirmaram ser consciência da relevante relação, porém mais da metade não soube justificá-la, o que infere a incapacidade, falta de informações e/ ou embasamento teórico para responder a pergunta. Outros 7\% responderam que essa relação se refere ao letramento, na escrita. Tisi ${ }^{(16)}$ nos mostra que a escrita consiste em um aprendizado motor, ou seja, não adianta massacrar as crianças com repetições das letras se antes disso não for trabalhado com elas questões como: ritmo, lateralidade, coordenação motora fina para segurar o lápis, coordenação espaço-temporal, dentre outras estruturas psicomotoras necessárias, no caso, ao letramento e a alfabetização.

Outro grupo se direcionou, de forma limitada, à relação existente da atividade física com o relacionamento entre as crianças. Um graduando ressaltou a importância de se trabaIharem os sentidos das crianças e outro justificou essa relação ser comprovada cientificamente; porém, não apresentaram evidências que justificassem sua reposta.

QUADRO 5. Relação entre o desenvolvimento motor e a cognição?

\begin{tabular}{|c|c|c|c|c|}
\hline RESPOSTAS & INFERÊNCIAS/CATEGORIAS & INDIVÍDUOS & QUANTIDADE & PORCENTAGEM \\
\hline \multirow{6}{*}{$\begin{array}{l}\text { Sim (13) } \\
\text { Não (0) }\end{array}$} & Auxilia na escrita & A11 & 1 & $7.69 \%$ \\
\hline & Comprovado cientificamente & $\mathrm{A} 12$ & 1 & $7.69 \%$ \\
\hline & Melhora no relacionamento & A6 & 1 & $7.69 \%$ \\
\hline & Não Justificaram & $\begin{array}{c}\mathrm{A} 1, \mathrm{~A} 2, \mathrm{~A} 4, \mathrm{~A} 7, \mathrm{~A} 8, \\
\mathrm{~A} 9, \mathrm{~A} 13\end{array}$ & 7 & $53.84 \%$ \\
\hline & $\begin{array}{l}\text { Relação entre desenvolvimento motor } \\
\text { e cognição }\end{array}$ & A3, A5, A10, A11 & 4 & $30.76 \%$ \\
\hline & Trabalha com os sentidos & A3 & 1 & $7.69 \%$ \\
\hline
\end{tabular}


Quanto à importância da brincadeira (QUADRO 6), 46\% referiu-se ao desenvolvimento da autoestima, criatividade, autonomia e da expressão infantil e outros $46 \%$ ressaltou as relações sociais e as interações produzidas pelas crianças durante 0 ato de brincar. As respostas apresentaram, no entanto, pouco embasamento teórico, destituídas de referências consistentes acerca do desenvolvimento social da criança através dos jogos, amadurecimento motor e estimulo lúdicos através da brincadeira, etc. Um entrevistado ressaltou a consciência corporal estimulada através da brincadeira, porém não se aprofundou na questão.

QUADRO 6. Importância do brincar no desenvolvimento integral da criança.

\begin{tabular}{lccc}
\hline INFERÊNCIAS/CATEGORIAS & INDIVÍDUOS & QUANTIDADE & PORCENTAGEM \\
\hline Desenvolvimento integral & $\mathrm{A} 3, \mathrm{~A} 4, \mathrm{~A} 5, \mathrm{~A} 12$ & 4 & $30.76 \%$ \\
\hline Autonomia/Criatividade/ Autoestima/Expressão & $\mathrm{A} 2, \mathrm{~A} 4, \mathrm{~A} 5, \mathrm{~A} 9, \mathrm{~A} 11, \mathrm{~A} 12$ & 6 & $46.15 \%$ \\
\hline Relações Sociais/Interações & $\mathrm{A} 4, \mathrm{~A} 5, \mathrm{~A} 7, \mathrm{~A} 8, \mathrm{~A} 10, \mathrm{~A} 11$ & 6 & $46.15 \%$ \\
\hline Desenvolvimento motor & $\mathrm{A} 3, \mathrm{Al1}$ & 2 & $15.38 \%$ \\
\hline Lúdico/Interesse/Imaginação/ Descobrir o mundo & $\mathrm{A} 1, \mathrm{~A} 2, \mathrm{~A} 5, \mathrm{~A} 6, \mathrm{~A} 9, \mathrm{~A} 10$ & 6 & $46.15 \%$ \\
\hline Assimilação & $\mathrm{A} 13$ & 1 & $7.69 \%$
\end{tabular}

\section{DISCUSSÃO}

A sociedade ainda tem a concepção de que para se trabalhar com crianças de 3 a 5 anos,

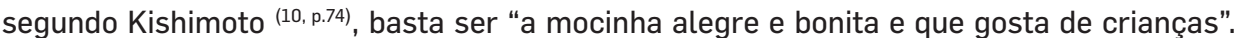
Ainda persiste o pensamento de que não se necessita de muito preparo e nem muita qualificação para se ministrar aulas para essa faixa etária.

A análise de conteúdo das entrevistas aqui realizada corrobora tal fato quando $15 \%$ dos graduandos responderam querer trabalhar com Educação Infantil pelo prazer de estar em contato com crianças. Tal fato ratifica o viés assistencialista que ainda hoje abarca o imaginário social sobre o seguimento. Um dos pontos a serem refletidos e discutidos no campo da Educação Infantil diz respeito, segundo Ayoub (2, p.53), "à organização geral dos currículos de creches e pré-escolas, levando em consideração a indissociabilidade entre educação e cuidado no sentido de se buscar uma superação da dicotomia educação/ assistência" Tal imaginário parece ser estendido também à área de Educação Física. As potencialidades das propostas da abordagem da cultura corporal do movimento às crianças e bebês são desconhecidas, não apenas para o público leigo, mas também para os próprios atores inseridos neste seguimento da Educação Básica, como é o caso dos futuros pedagogos.

As categorias levantadas na análise inferiram um vasto repertório de disciplinas que propiciam um embasamento teórico-prático aos profissionais nos currículos de Educação Física, porém, em relação aos pedagogos, o mesmo não foi encontrado. Encontramos em alguns currículos uma única disciplina especifica da Educação Física, apresentada de forma eletiva.
Podemos nos questionar a abrangência desta disciplina em formar um profissional capaz de desenvolver a criança integralmente, inclusive em termos psicomotores. É fato a importância da compreensão dos princípios dos jogos e das brincadeiras para tal, - como consta ser o objetivo geral da disciplina - mas a redução da Educação Física a tal temática inviabiliza o aprendizado da riqueza da cultura corporal do movimento humano por parte dos alunos.

Pensamos se uma disciplina será suficiente para um futuro professor compreender as características motoras, cognitiva, afetivas e socioculturais daquela criança em movimento. Questionamos ainda se profissionais isentos de saberes biomecânicos, fisiológicos e anatômicos, relacionados à formação e desenvolvimento da criança, são capazes de fomentar estímulos da cultura corporal coerentes com a proposta Zona de Desenvolvimento Proximal do aluno que, segundo Vygostsky ${ }^{(20)}$, são necessários à real aprendizagem por parte da criança.

O professor de Educação Física consciente da importância do movimento como expressão, não só de habilidades motoras mas também de uma rede de signos e significados que marca o entrelugar que esta criança se insere e vem sendo percebida, vai trabalhar, segundo Wajskop (22) como mediador intencional, organizado e parceiro do mundo ante a criança, afirmando seu engrama motor culturalmente já construído. Tal prática deve influenciar e aportar o olhar de toda a instituição.

professor de Educação Física vai, sobretudo, mediar saberes ante toda a instituição de Educação Infantil construída e ainda marcada por uma lógica de saber moderno, que desconhece a importância da cultura corporal como forma de posicionamento desse ser agente passivo da cultura. Tomar a criança como centro do processo, aprofunda ainda Wajskop ${ }^{(22)}$, significa em primeiro pensá-la não como futuro adulto em formação, mas um ser "em devir" que se expressa hoje, enquanto integrante parceiro da Educação Infantil com quem negociamos afetos, regras, saberes e limites. Pensamos: Como professores sem essas informações vai influenciar e, se necessário modificar, toda uma cultura escolar que ainda desqualifica a Educação Física nas escolas?

Os dados afirmaram ainda que os próprios graduandos de Pedagogia não se sentiam seguros para lecionar conteúdos específicos de Educação Física às crianças. Uma entrevista corroborou o fato de haver risco para as crianças caso a prática de aulas realizada por profissionais não formados na área, fato corroborado por Silveira ${ }^{(15)}$. Segundo esta autora:

A prática de atividade física é sempre importante para se ter uma boa qualidade de vida mas feita de forma errada, pode trazer riscos de lesões. As lesões podem ocorrer por gestos motores realizados incorretamente, onde as posturas incorretas colocam a coluna vertebral e as articulações em descompensação de cargas, riscos de lesões articulares e desvios posturais, levando o corpo à fadiga muscular e mental, causando muitas vezes excessos de treinamento, o conhecido overtraining. A importância do profissional de Educação Física é extrema nesta área, pois ele é o único profissional habilitado e que tem conhecimento para ministrar a prática da atividade física e do esporte com segurança e coerência na busca dos objetivos procurados pelo praticante. 
Quando questionados acerca da importância da Educação Física na grade na Educação Infantil, todos os graduandos foram unânimes em ressaltar sua importância. 7\%, no entanto, utilizou como argumento o tempo de lazer, para "descarregar energias". Outros 7\% ressaltou sua importância como espaço alternativo à aprendizagem teórica/ cognitiva, respostas que corroboram o ideário cartesiano que ainda determina as concepções de corpo que transpassam tanto atores escolares como projetos políticos pedagógicos das escolas.

Embora conscientes de que o corpo é, na escola, o veículo através do qual o indivíduo se expressa, afirma Strazzacaappa ${ }^{(16)}$ que o movimento corporal sempre funcionou como uma "moeda de troca". A autora defende que as atitudes disciplinares utilizadas ainda hoje nas instituições de ensino não se diferenciam muito das de outrora. Professores e coordenadores impõem a imobilidade física como forma de punição, e a liberdade de se movimentar como prêmio. Reconhece-se o indisciplinado pelo excesso de movimento que produz. Desta forma, destitui da criança qualquer possibilidade de conhecer seu próprio corpo com limites e potencialidades.

A origem dessa concepção bipartida de Homem surge antes da formalização da escola como instituição social e data do século XVII. Descartes ${ }^{(9)}$, na intenção de definir o sujeito e sua realidade, postula a existência das distintas categorias res extensa e a res cogitans. A primeira refere-se à substância tridimensional, material, explicável fisicamente; e a segunda categoria Descartes utiliza para determinar a substância pensante, independente da matéria, invisível e incomensurável fisicamente. 0 filósofo define então uma nova concepção de natureza humana que reverbera em séculos posteriores aportando epistemologicamente concepções de homem e corpo produzidas pela escola, como corrobora as respostas acima.

Buscamos ainda compreender as concepções dos entrevistados acerca das possíveis relações existentes entre o desenvolvimento motor e cognitivo nas crianças, com o intuito de corroborar as impressões dualistas obtidas, por nós, nas respostas anteriormente apresentadas. Apesar de ser unânime a afirmação de corroborarem haver alguma relação, todos os graduandos não souberam bem justificá-la, o que infere a incapacidade, falta de informações e/ ou embasamento teórico para responder a pergunta. Uma aluna respondeu que essa relação se refere ao letramento, na escrita.

Tisi ${ }^{(16)}$ nos mostra que a escrita consiste em um aprendizado motor, ou seja, não adianta massacrar as crianças com repetições das letras se antes disso não for trabalhado com elas questões como ritmo, lateralidade, coordenação motora fina para segurar o lápis, coordenação espaço-temporal, dentre outras estruturas psicomotoras necessárias, no caso, ao letramento e a alfabetização. Parece, de acordo com as respostas, não haver conhecimento acerca de tais saberes docentes.

As respostas direcionadas a uma questão básica da formação do profissional de Educação Física e relevante aos docentes que lecionarão às crianças parece significar as fragilidades da formação do pedagogo para construir e propor atividades psicomotoras que promovam além do conhecimento do contexto sociocultural no qual as crianças se encontram, o desenvolvimento de estruturas psicomotoras básicas para a concretização da alfabetização.

As entrevistas corroboraram o que previamente foi inferido na análise dos currículos: os cursos de Pedagogia são incipientes na promoção de conteúdos imprescindíveis para se desenvolver integral e, sobretudo, psicomotoramente, crianças através da abordagem da cultura corporal do movimento. Das entrevistas inferimos, ainda, a insegurança e negação por parte dos graduandos em Pedagogia em cumprirem a função dos professores de Educação Física, dentro das instituições de Educação Infantil.

Foi evidenciado que gestos motores realizados de forma incorreta colocam a coluna vertebral e as articulações em descompensação de cargas, promovendo possíveis lesões articulares e desvios posturais. Foi ressaltado ainda que a inexistência de informações inerentes às áreas da Biomecânica do Movimento, Aprendizagem Motora, Fisiologia e Anatomia impossibilitam que o profissional responsável planeje atividades congruentes com a Zona de Desenvolvimento Proximal das crianças. Tal fato, potencialmente, atrasará e/ ou colocará em risco seu desenvolvimento e sua maturação.

\section{CONCLUSÕES}

Por fim, a pesquisa apresentada deixou clara: (1) a ausência de conteúdos biomecânicos, fisiológicos e anatômicos relacionados intrinsecamente à formação e desenvolvimento psicomotor da criança por parte dos graduandos em Pedagogia; (2) a existência de apenas uma disciplina eletiva de Educação Física nos currículos de Pedagogia; (3) propostas ementárias, no currículo de Pedagogia, formuladas com atividades psicomotoras incoerentes à fase de desenvolvimento motor infantil e; (4) conteúdos que possivelmente provocariam, nas crianças de zero a cinco anos, atraso na aprendizagem de habilidades motoras fundamentais se, de acordo com o currículo de Pedagogia, fossem propostos. Em virtude de tudo o que foi mencionado podemos concluir que os pedagogos não são preparados para ministrarem aulas de Educação Física no seguimento da Educação Infantil.

Desejamos, com esse trabalho, contribuir para que a legislação seja respeitada, uma vez que aqui apresentamos dados consistentes acerca tanto da vacuidade dos currículos de Pedagogia de abarcarem as especificidades da formação de um professor de Educação Física, assim como dos riscos da sua inexistência no seguimento da Educação Infantil. Por fim, fica clara a urgência de se garantir uma formação adequada àqueles que legalmente devem cumprir com seu papel de educador físico de forma consistente neste importante seguimento da Educação Básica. 
1. Antunes M (2002). Psicologia e educação em periódicos brasileiros anteriores a 1962. Psic Escolar Educ 6(2): 193-200

2. Ayoub E (2001). Reflexões sobre a educação física na educação infantil. Rev Paul Educ Fís 4: 53-60.

3. Bardin L (1977). Análise de conteúdo. Lisboa: Ediçōes 70.

4. Bento JO (1987). Planejamento e avaliação em edu-

cação física. Lisboa: Livros Horizonte.

5. Brasil. Ministério Educação Cultura (1996). P

.

6. Brasil. Ministério Educação Cultura Secretaria Edu-

cação Infantil (1998). Referencial curricular nacional

para a educação infantil. Brasília: MEC/SEF.

7. Brasil, Senado Federal (1996). Lei de Diretrizes e Bases da Educação Nacional: no 9394/96. Brasília/DF.

8. Burger LC, Krug HN (2009). Educação física esco-

lar: um olhar para a educação Infantil. EF Desportes

13(130). Disponivel em http://www.efdeportes.com/

index.php/EFDeportes

9. Descartes R (2006). Discurso do método. Trad. Mio-

ranza C. São Paulo, SP: Editora Escala.

10. Kishimoto T (1999). Política de formação profissional para a educação infantil: pedagogia e normal superior. Educ Soc 68: 61-79.

11. Negrine A (2002). 0 corpo na educação infantil. Caxias do Sul: EDUSC.

12. Nóvoa A (1992). As organizações escolares em análise. Lisboa: Publicações Dom Quixote.

13. Rio de Janeiro, Assembleia Legislativa do Rio de Janeiro (2014). Projeto de Lei Complementar número 3002/2014. Disponivel em http://alerjln1.alerj.r.j.gov. br/scproll15.nsf/012cfef1f272c0ec832566ec001 8d831/ec095471b2edfe1583257ce600721cc0?Open Document\&ExpandSection $=-1$

14. Silva AH, Fossa MT (2015), Análise de conteúdo: exemplo de aplicação de técnicas para analisar dados qualitativos. Quali@as 17(1).

15. Silveira EF (2014). Atividade física sem orientação: riscos para quem pratica. EFDeportes.com 19(192). Disponivel em http://www.efdeportes.com/efd192/ atividade-fisica-sem-orientacao-riscos.htm

16. Strazzacappa M (2001). A educação e a fabrica de corpos: a dança na escola. Cad Cedes 21 (53): 69-83. 17. Tani G (1988). Educacão física escolar: uma abor(7). Thi $(1988)$. dagem desenvolvimentist versidade des

18. Tardif M (2002). Saberes docentes e formação profissional. Rio de Janeiro: Vozes Editora.
9. Tisi L (2004). Educação física e a alfabetização. Rio de Janeiro: Sprint.

20. Vygotsky L (1966). Mind in society: the development of higher psychological processes. Cambridge, Harvard University Press

21. Wajskop G (1995). 0 brincar na educação infantil. Cad Pesq 92: 62-69.

2. Wajskop G (2012). Brincar na educação infantil:

uma história que se repete. São Paulo: Cortez.
Fernando J. Santos

Hugo G. Louro ${ }^{2}$

Teresa P. Figueiredo

Hélder M. Lopes ${ }^{3}$

José J. Rodrigues

Instituto Politécnico de Setúba Escola Superior de Educação

Setúbal, Portugal

${ }^{2}$ Instituto Politécnico de Santarém

- Escola Superior de Desporto

de Rio Maior, Rio Maior, Portugal

3 Universidade da Madeira,

Madeira, Portugal

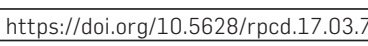

SUBMISSÃO: 16 de Julho de 2017

ACEITAÇ̃̃o: 30 de Dezembro de 2017

\section{RESUMO}

O presente estudo pretendeu analisar as expectativas e a auto perceção de treinadores de jovens sobre o objetivo, forma e direção da instrução emitida em competição. Foram aplicados, em oito competições dos campeonatos nacionais de Portugal, o Questionário sobre as Expectativas da Instrução e Comportamento dos Atletas em Competição e o Questionário sobre a Auto Perceção da Instrução e Perceção do Comportamento dos Atletas em Competição. Participaram neste estudo quatro treinadores de futebol jovem, cujas equipas competiam no campeonato nacional - juniores A (17-18 anos) e B (15-16 anos). 0 tratamento estatístico foi feito através da análise descritiva e, tendo em conta o teste de normalidade, as correlações foram verificadas através dos coeficientes de correlação de Pearson e Spearman. Verificámos que os treinadores tinham expectativas e a perceção de emitirem instruções com um objetivo afetivo e avaliativo positivo, sob a forma auditiva-visual. Além disso, esperavam emitir mais instrução à equipa, enquanto que, ao nível da perceção, consideraram ter emitido mais instrução ao atleta. Registámos correlações positivas entre as expectativas e perceção nas categorias instrução, avaliativa positiva, descritiva, prescritiva e afetividade negativa. Concluímos que existia pouca congruência entre as expectativas e a perceção do treinador relativamente à instrução emitida durante a competição.

Correspondência: Fernando Jorge Lourenço dos Santos. Instituto Politécnico de Setúbal - Escola Superior de Educação. Campus do IPS - Estefanilha, 2910-761 Setúbal. (filsantos@gmail.com) 